\title{
Adapting the DIPLOMACY board game concept for 21st century International Relations teaching
}

\section{Mattlin, Mikael}

2018-12

Mattlin , M 2018 , ' Adapting the DIPLOMACY board game concept for 21st century International Relations teaching ' , Simulation \& Gaming , vol. 49 , no. 6 , pp. 735-750 . https://doi.org/10.1177/10468

http://hdl.handle.net/10138/272994

https://doi.org/10.1177/1046878118788905

acceptedVersion

Downloaded from Helda, University of Helsinki institutional repository.

This is an electronic reprint of the original article.

This reprint may differ from the original in pagination and typographic detail.

Please cite the original version. 
Mattlin, Mikael (2018), "Adapting the DIPLOMACY Board Game Concept for $21^{\text {st }}$

Century International Relations Teaching," Simulation \& Gaming

http://journals.sagepub.com/doi/pdf/10.1177/1046878118788905

Copyright @ 2018 SAGE Publications. Reprinted by permission of SAGE Publications.

\section{Adapting the DIPLOMACY Board Game Concept}

\section{for 21st Century International Relations Teaching}

The classical board game DIPLOMACY (Avalon Hill / Hasbro) was developed by Allan

B. Calhamer (Calhamer, 1999) in the 1950s. For decades, it has been a popular board game, postal game and online game. DIPLOMACY has also been used as a teaching platform for international relations (IR), diplomacy and dynamic decision-making (Asal, 2005; Eskin, 2004; Gattie, 2004).

While many aspects of the game make it useful for university IR teaching, there are also some shortcomings. DIPLOMACY has been considered a close approximation of an anarchical self-help world, where states ultimately can rely only on themselves, other protagonists' words can never be fully trusted and betrayal of promises frequently occurs. While this may have been a relatively accurate description of the ruthless pre-WWI European secret diplomacy, which the game depicts, and that Woodrow Wilson so detested (Kissinger, 1994), it's relation to today's far more institutionalized and less 
security-centered international diplomacy is tenuous, at best. Realism has a long history as foreign policy practice and as an IR theory. However, the dog-eat-dog world portrayed in DIPLOMACY is not particularly useful as a simulation of actual contemporaneous international relations - unless you happen to be stationed in Syria.

If we see game design through the prism of simulation-as-microworld (Rieber, 1996; Romme, 2004) and the aim is to construct a good learning environment for international relations through the parameters and rules created within this microworld, then the original DIPLOMACY design can be improved upon. Niv-Solomon et al. (2009) have shown that actors participating in international, simulated negotiations adapt to the rules and norms of the interaction environment. Other researchers have similarly indicated that changing the game rules in an IR role-playing game can produce a game outcome that follows a different theoretical logic (Tamai et al., 2016).

In my application of the DIPLOMACY board game to university teaching, I have adapted the game in several ways to make it more useful for IR teaching purposes, beyond letting students experience the realist worldview. New elements include team play, employing a dedicated peace mediator team, altering win rules to enable mediated and negotiated outcomes, and adding post game debriefing discussions on different cultures of anarchy. The result has been a well-integrated course that students have highly appreciated, based on three year's written and oral feedback. An overwhelming majority 
of students have considered the course better than more traditional forms of learning, and several students have spontaneously indicated that it is the best or one of the best courses that they have ever attended.

\section{Board Games and Negotiation Simulations as Teaching Tools}

In recent years, there has been increased scholarly interest in using both purpose-designed (Mason \& Patterson, 2012; Huang \& Levinson, 2012; Männarmaa, 2015; Hoy, 2018) and classical board games (Drake \& Sung, 2011; Paino \& Chin, 2011) in university teaching. Classical board games can be powerful teaching tools due to their simplicity, constrained game play and transparency (Zagal et al., 2006). In contrast, one of the limitations of a computer-based game such as CIVILIZATION, which has also been used to teach IR, is its complexity and the required time-commitment to learn the game (Weir \& Baranowski,

2011). However, sometimes the original board game logic and rules need to be modified to better suit educational purposes. For example, Paino and Chin successfully modified MONOPOLY for use in an undergraduate deviance class to teach difficult material, especially critical theory (Paino \& Chin, 2011). Similarly, Coghlan and Huggins (2004) modified MONOPOLY to emphasize structural inequalities by dividing the class into different groups representing different social classes. 
DIPLOMACY differs from many other strategy board games in ways that make it appropriate for educational purposes. The game rules are strategic, abstract and simple, which underlines its character as a simulation of negotiations and puts emphasis on social interaction skills. Various negotiation simulations are commonly used as teaching tools, and their pedagogical usefulness has long been documented in educational literature (Rieber, 1996; Hess, 1999; Brown \& King, 2000). In gaming simulations, students own activity and discussions are central to the learning experience. They represent the instructional artifact that most closely matches the characteristics that research has shown to be related to intrinsic motivation and motivating learning environments: curiosity, challenge, fantasy and control (Rieber, 1996; Vermunt, 2007). Simulations enliven the contents taught, clarify theory and activate students to use their own thinking and judgment through the competitive element typically involved. They are a form of active learning, and a sub-set of problem-based learning (Hess 1999; Brown \& King, 2000; Asal, 2005; Loggins, 2009; Kauneckis and Auer, 2013).

One advantage of good simulation games is that they approximate real world decision-making with all its complexity, human interaction, interdependence, wheeling and dealing, uncertainty and compromises. However, a disadvantage of low-tech and notech games, is that they are only able to handle a limited cognitive load and it is usually 
not possible to store large quantities of information for analysis purposes, or replay scenarios (Mayer, 2009).

While students are often able to think abstractly about the various elements involved in foreign policy decision-making, they tend to forget about this complexity when analyzing real world political situations (Loggins, 2009; Hudson, 2014). Despite its relatively simple game rules, DIPLOMACY underlines the complexity involved in foreign policy decision-making. Negotiations, psychology, cooperation and game theoretical thinking figure prominently in DIPLOMACY, which makes the game inherently useful to IR teaching, especially from an actor perspective. Game orders are resolved simultaneously, which mimics actual real-time behavior and makes the game a good low-cost simulation of dynamic decision-making (Gattie, 2004; cf. Kuperman, 2010). Furthermore, the game contains no chance elements, apart from the initial draw of the country played.

However, DIPLOMACY has its limitations when it comes to teaching. One limitation is a common problem with using games in teaching: that the medium (game) becomes too dominant in relation to the pedagogical purposes, that is, the game and learning process are not integrated well enough (Asal, 2005). A related problem is the gaming the game phenomenon of students adopting a gamer mode that is optimal for winning the game, but suboptimal for the educational objectives (Frank, 2012). Students 
may become so absorbed with the game itself that, while playing the game gives enjoyment, it also interferes with the learning objectives (Rieber \& Noah, 2008).

A second, more DIPLOMACY-specific shortcoming, is the game's approximation of a worldview akin to an extreme version of realism, which (ironically) is not a realistic depiction of international relations in the 21 st century. One of the advantages of DIPLOMACY is that it allows students to reflect between the world created by the game's rules, the world as described by IR theories and students' own worldviews. The game has previously been used in IR teaching mainly to allow students a chance to reflect on how the world would work if it worked in the way that realism assumes it does. Pedagogically, the game has been regarded as a useful simulation especially because it tends to spur fierce class discussions on realism (Asal, 2005).

In the original game set-up players follow the famous realist maxim by Thucydides that "the strong do what they can and the weak suffer what they must". Showing students how quickly they get engulfed by the logic of a self-help world, is educational in itselfleading to a deeper understanding of realpolitik, or power political behaviour (Johnston, 1995), that students can then debate, and reject if they wish. Nonetheless, the game can be criticized for naturalizing an actor-oriented perspective, which makes thinking of IR in terms of relations difficult (cf. Tickner, 2005). 
Among current IR theories, the basic logic of DIPLOMACY mimics relatively closely John Mearsheimer's (2001) offensive realism. Mearsheimer's position, while influential, is not a mainstream position among IR scholars, especially in Europe, which broadly adheres to more constructivist notions. Mearsheimer essentially argues that international relations have not fundamentally changed in character from what they have been throughout the ages. In an anarchic world, states are still primarily oriented towards power and their own security and can ultimately only rely on themselves (self-help). Great powers look for opportunities to gain power over each other, that is they care more about relative than absolute gains and take advantage of opportunities to increase their relative power whenever they can, that is, they are revisionists at their core. This point sets Mearsheimer's offensive realism apart from the defensive realism of Kenneth Waltz, which tends to regard states as more status quo -oriented (maintaining their position within the system through balance-of-power and other means).

In DIPLOMACY, the Mearsheimer worldview is accentuated and overemphasizes the conflictual nature of international relations. Individual players ceaselessly try to gain an advantage over each other by taking and controlling supply centers on the board through military moves and engaging in negotiations and verbal as well as non-verbal signaling, which includes lies and the breaking of promises. Since the system is anarchic, no higher authority can enforce contracts. Approximating the Hobbesian logic of anarchy, 
war may break out at any time and "unfit" actors will be eliminated through conquest, while stronger players will tend to engage in power-balancing (Wendt, 2010: 265-266). Being nice is not a recipe for game success. One of the infamous features of DIPLOMACY is that it tends to bring out strong emotions and may even ruin social relationships (Eskin, 2004; Asal, 2005). Successful game play is usually a combination of negotiation skills, a strategic eye and engendering trust, while biding one's time and breaking commitments only when the benefits outweigh the costs. Importantly, however, it is almost impossible to win the game without breaking promises at some point. The trick is to do it sparingly and at opportune moments. In other words, backstabbing is an advantageous competitive manoeuver in an otherwise cooperative game (Zagal et al., 2006).

I believe that the microcosm created by the original game rules can be improved upon by both showing the logic of how a realist self-help world operates, and then letting students discover and debate alternatives. In this context, constructivist IR scholar Alexander Wendt's notion of cultures of anarchy has been useful. Building on earlier work by English School theorists (Wight, 1991; Bull, 1995), Wendt showed that, while realists tend to believe that the anarchical system forces its members (states) to behave in certain ways in order to survive, the anarchical self-help system of realism is only one possible culture of anarchy. Wendt called this a Hobbesian culture, where interaction is 
based on enmity. Other basic possibilities were a Lockean culture based on rivalry and a Kantian culture based on friendship. Instead of seeing the structure of the international system in materialist terms, as Mearsheimer and Waltz do, Wendt understands this structure as forming the system's culture. Furthermore, this culture can take several forms and may be internalized by participants in the system to various degrees, depending on whether internalization is based mainly on force, self-interest or legitimacy (Wendt, 2010). In my courses, I have incorporated the cultures of anarchy -concept to post-game debriefing discussions. Debriefing discussions serve an important role in deepening learning (Crookall, 2010).

\section{Course Design and Game Modifications}

In my course design that utilizes the board game version of DIPLOMACY, I have attempted to address these two shortcomings. To address the first problem, I designed the course so that all teaching and learning elements support each other, and so that the game forms a natural part of the learning process, rather than being only tangentially related to the taught content. While game-related negotiations form an integral part of the teaching concept, it would not work well without the other course elements, which include regular lectures and class discussions, a compulsory literature package (ca 600 pages), weekly student discussions on an online learning platform, small group class discussions, a 
learning diary and two-way feedback. All in all, the course has consisted of seven 1,5hour lectures and a maximum of 10 hours of game play.

Teaching and learning proceed on several levels and connections between these levels are actively sought and developed. Given that the course is an IR course, real-time topical world events are also brought into the discussions (for example related to Syria, North-Korea, China or Ukraine). The compulsory course syllabus contains literature that relates to various aspects of the game and is designed to broadly follow the course of the game. The course literature begins with sections from books that deal with the history of diplomatic negotiations of the time and follows up with theoretical literature on the diplomatic negotiation process and on geopolitics and balance of power. It then turns to consider political psychology and decision-makers, comparative collective security arrangements, as well as historical causality and counterfactuals. Finally students read up on Wendt's different logics of anarchy.

The course has been designed as a very intensive, continuously on-going activity. Before each lecture, the week's compulsory reading is digested. The literature is discussed in an interactive class, including in small groups. Towards the end of the lecture, a weekly discussion assignment is given. The lecture is followed by a lunch break, after which students play the board game for two hours in class. In between lecture and game sessions, students have one week's time to digest next week's course literature and 
additional materials that the teacher provides online, participate in the online discussion, wage game-related negotiations and conduct public diplomacy (in the online learning environment), as well as write their course diary. The learning model I implemented shares some elements with the flipped classroom notion, although differs in other aspects.

In the final evaluation, the course diary, game performance, online discussion and class activity all account for $25 \%$ of the final grade. The course finishes with a thorough debriefing and feedback lecture. Students analyze each other's game strategies and styles, how the actions of others have been interpreted, as well as reflect on the learning experience. These post-game debriefing discussions have been most illuminating, as students often discover that other players interpret their actions differently from how they themselves perceive these actions; for example, someone might inadvertently signal distrust even when trying to send messages of trust. Students thus also learn about themselves and their own behavior under time-pressures and stress. In the course diary, the objective is to bring all the elements of the course together; from the course literature through class discussions and game events to real-time world events. Students are given much latitude in determining how they write the course diary and creativity is emphasized as an evaluation criteria.

The second, more game-specific shortcoming of DIPLOMACY as an IR teaching tool, is that it arguably depicts a microcosm of the world that is neither entirely realistic 
in the 21 st century, nor normatively desirable; a world breeding on distrust, the breaking of commitments and might-makes-right type behavior. In order to remedy this shortcoming, I introduced several elements that are not available in the original game design. Table 1 summarizes the main modifications introduced to the game in order to make it more suitable for IR teaching.

Table 1. Modifications to DIPLOMACY gameplay for IR teaching

\begin{tabular}{|c|c|c|}
\hline $\begin{array}{l}\text { Original game } \\
\text { version }\end{array}$ & $\begin{array}{l}\text { Modified for } \\
\text { teaching }\end{array}$ & Educational aims \\
\hline Single player & Team play & $\begin{array}{l}\text { Practicing intra-team } \\
\text { negotiations (domestic politics) }\end{array}$ \\
\hline - & $\begin{array}{l}\text { Peace mediator } \\
\text { team }\end{array}$ & Developing peace-making skills \\
\hline $\begin{array}{l}\text { Winning by } \\
\text { board domination } \\
\text { (or by draw) }\end{array}$ & $\begin{array}{l}\text { Winning by } \\
\text { negotiated } \\
\text { outcome }\end{array}$ & $\begin{array}{l}\text { Emphasizing the game's } \\
\text { negotiation aspects instead of its } \\
\text { strategic aspects; removing the } \\
\text { need for betrayal to win }\end{array}$ \\
\hline- & $\begin{array}{l}\text { Post-game } \\
\text { reflections on } \\
\text { different cultures } \\
\text { of anarchy }\end{array}$ & $\begin{array}{l}\text { Showing that the game logic } \\
\text { approximating offensive realism } \\
\text { is only one possibility and that by } \\
\text { altering the goals and dynamic } \\
\text { different logics may emerge }\end{array}$ \\
\hline
\end{tabular}

Students play in two-player teams instead of individually, which further emphasizes the negotiation and cooperation aspects of the game and injects an element of "domestic 
politics" into negotiations. Robert Putnam famously argued that international relations is a two-level game that takes place both in diplomatic negotiations and in domestic politics settings. International agreements also need to be sold domestically (Putnam, 1988). Teams have to agree internally on their intra-team roles (for example, chief negotiator and chief strategist) and resolve potential internal disputes that sometimes occur, especially given time-constraints. In the course design, players do not get to choose their own team-mates. They are assigned to a team alphabetically. Sometimes teams develop into a well working duo. At other times, differences in personality, game style preferences and ways of reading the game and other players cause visible frictions that are either resolved or affect game performance.

DIPLOMACY is a negotiation simulation more than a war simulation. Ultimately the game objective is to dominate the game board. As the game rules state "in order to survive, a player needs help from others. In order to win the game, a player must eventually stand alone." (DIPLOMACY game rules) The game objective is thus not conducive to reaching a negotiated and shared solution. After all, who would gladly want to accept terms that are dictated by someone who has conquered more than half of everything? That situation is more akin to the terms handed down by military victors following unconditional surrender by their enemies, rather than the more mundane giveand-take of everyday IR negotiations. While the game rules allow for ending the game 
with agreement (usually because of stalemated situations), in this case, no peacemakers are employed and all players share equally in the draw.

To remedy this shortcoming, I introduced another self-developed game element: a special peace-mediating team. During the first course, I experimented with assigning a peace-making role to the team who was first dropped out of the game. However, this did not work well. The students assigned to this new role had trouble switching from being players in the game to being mediators, and other players did not regard them as neutral arbiters. In subsequent courses, I have assigned the peace-mediating role to one team from the start, which has worked much better. Players, who are dropped out of the game, still retain the option of joining the peace mediating team, if they wish.

At the beginning of the game, the role of peace mediators is peripheral, as students typically are excited about playing the game and certainly not interested in finding a quick way to end it. As the game wears on and battle fatigue sets in, the role of neutral peace mediators grows. This mimics the real thing. Typically, war-waging parties are not interested in making peace as long as the battlefield situation is in flux and gains can be expected from continued fighting. When events on the battlefield become bogged down, casualties and costs grow and no end is in sight through continued fighting. Under such circumstances, peace mediators may find combatants more ready to use their services.

In order for the peace mediators' role to work, I introduced another subtle 
modification to the winning rule. Instead of winning by domination or draw, the game can also be ended by a negotiated solution, whereby all teams remaining in the game agree on the rank order of teams. This allows for and encourages a negotiated solution instead of a winner-takes-all outcome. The peace deal needs to be agreed in writing and signed by all combatant parties still left in the game. The negotiated final ranking also needs to be reflected on the game board, if need be by effecting orderly withdrawals and ceding territory to comply with the negotiated agreement. While no actual prizes are given to game winners, success in the game has a slight effect on the final grade, as it accounts for a quarter of it. More important than this seems to be the social prestige gained among fellow students by performing well in the game.

Both times that we used peace mediators in the described way, the game ended in a negotiated agreement with the assistance of peace mediators. However, the 2016 peace mediators failed spectacularly in their first attempt at peace negotiations. Having learned some lessons, for the second attempt the peace-mediating team had done its homework and worked out a very meticulous plan for peace. The plan was implemented through a round of sequenced negotiations that managed to eventually get everyone on board, despite hesitancy on the part of one team (Russia), which looked set to jolt up from second to first place if the game had continued.

In the 2017 course, the mediated outcome came about surprisingly easily. A 
contributing factor was undoubtedly battle fatigue that was setting in, given that the game had been emotionally taxing. Peace mediators proposed a peace plan, which all but one team was ready to accept. The Italian team took an assertive stance and initially refused to accept the agreement, unless another team gave them a chunk of territory. The other team quickly dismissed this as an opportunistic move and refused to give in. The Italian team eventually gave up on their demands and accepted the agreement.

Recent research on diplomatic signaling has suggested that making higher demands can increase perceptions of a state's resolve to fight for better outcomes under two conditions. Negotiating parties must share in the bargaining surplus from avoiding war, which tends to occur in a bargaining process, or when goods are only partially divisible. Furthermore, higher demands must be less likely to be accepted even if the threat is credible, that is, compromise may prove impossible, even if the alternative is war. These conditions also entail that less resolved conflict parties do not necessarily have an incentive to imitate such signals. When the adversary is believed unlikely to accede to maximalist demands, offers of compromise will be made, even though this signals weakness. Signaling weakness is acceptable to less resolved states when they perceive that maximalist demands are likely to lead to no concession, whereas moderate demands are more likely to lead to moderate concessions (Trager, 2017).

While the analogy is not perfect, the trade demand signaling dynamic playing out 
between the United States and China in 2018 is illustrative, with U.S. President Trump signaling a willingness to fight a trade war by making outrageous demands, and China (as the less resolved party) trying to avoid a trade war and look for avenues of compromise through more moderate demands.

Finally, one last addition to the game is that for the last lecture students are required to read a section from a seminal book by Alexander Wendt on cultures of anarchy (Wendt, 2010). This is then discussed both in class and online. The game trajectory mimics a shift from enmity with zero-sum logic and pervasive security dilemmas towards rivalry, where gains can be negotiated and divided, albeit not quite reaching the point of building Kantian peaceful security communities. In the online discussion, students ponder which logic (or combination of logics) they envision will prevail in future real-world international relations.

One of the most interesting findings to emerge from these debriefings is that only one student (out of 31 students) has seen future international relations moving in the direction of a Hobbesian logic of anarchy, and even he placed the argument in the context of history moving in cycles, with the Hobbesian trend currently prevailing. Given that the same students have just spent several weeks engaged in a Hobbesian struggle to eliminate opponents and dominate the DIPLOMACY game, and real-world events in Syria, North Korea and Ukraine (discussed in class) have provided a bleak real-world backdrop, this 
is somewhat surprising. The most common view was that the future is open or will most likely be a combination of different logics (usually with the Hobbesian logic as the weakest element). The second-most common view was that the future would approximate the Lockean notion of rivalry. Two students (out of 31 students) even envisioned a more Kantian future. Since no pre-course survey on student attitudes was undertaken, it is not possible to deduce to what extent the course impacted on these views. However, at the very least one might tentatively conclude that playing DIPLOMACY in the manner done on this course did not seem to turn students into offensive realists. On the contrary, some students indicated in their feedback that they thought the syllabus should have included more non-realist literature.

An intriguing possibility for further theoretical development of DIPLOMACY would be to allow also for a Kantian ending, for example by introducing a third wincondition, that of successfully establishing and maintaining a security community among some or all teams. This would be a community, where members do not fight each other, but rather live in peace and welcome others to join their community, although they may still defend together against unprovoked external aggression (Table 2). 
Table 2. A proposal for three educational ways to end a DIPLOMACY game:

\begin{tabular}{|l|l|l|}
\hline $\begin{array}{l}\text { Underlying logic of } \\
\text { anarchy }\end{array}$ & Process of ending the game & Outcome \\
\hline $\begin{array}{l}\text { Hobbesian } \\
\text { (enmity) }\end{array}$ & $\begin{array}{l}\text { Winning by conquering over } \\
50 \% \text { of supply centres }\end{array}$ & Sole victor \\
\hline $\begin{array}{l}\text { Lockean } \\
(\text { rivalry })\end{array}$ & $\begin{array}{l}\text { Negotiated and mediated } \\
\text { solution }\end{array}$ & $\begin{array}{l}\text { Rank-order among } \\
\text { remaining teams }\end{array}$ \\
\hline $\begin{array}{l}\text { Kantian } \\
\text { friendship })\end{array}$ & $\begin{array}{l}\text { Gradual establishment and } \\
\text { maintenance of a security } \\
\text { community }\end{array}$ & $\begin{array}{l}\text { All teams participating in } \\
\text { the security community } \\
\text { share equally in the win }\end{array}$ \\
\hline
\end{tabular}

In a much-noted essay, Robert Cooper (2000) suggested that our world is composed of pre-modern, modern and post-modern states. The first operated in a Hobbesian world. Modern states (such as China and Russia) adhere to the sovereignty-emphasizing Lockean world established in Peace of Westphalia 1648. In contrast, many European states have been attempting to transcend sovereignty and build an ever-expanding security community of peaceful relations.

In DIPLOMACY, players initially inhabit a Hobbesian world. Against this background, an interesting event unfolded during one course. A student team, who had played an aggressive early game but for which the game was not going well, suddenly unilaterally proclaimed neutrality, and asked other teams to respect their neutrality. As 
this was a rather transparent bid to avert being eliminated from the game and other teams were still immersed in the Hobbesian logic, the move floundered disastrously. However, what if students are told initially that a Kantian world is also possible and one team proclaims a commitment to neutrality from the start? The outcome may turn out different.

Instead of forcing students to play by the original Hobbesian logic, such a game modification would allow students to choose their worldview and corresponding game strategy. It would turn the game into a contest over different ways of structuring state relations. Students could thus even attempt to transform the logic of anarchy into a Kantian one, which Wendt argues is difficult, but not impossible. Wendt argues that the building blocks for such a cultural change are a realization of interdependence, common fate and homogeneity, in conjunction with self-restraint, which he regards as essential (Wendt, 2010).

\section{Discussion of Student Feedback and Teaching Experiences}

In terms of student activity and motivation, my DIPLOMACY-based course design has been a success. I have collected systematic student feedback on all three courses using the same feedback form. In the beginning of the course, students have been made aware that the course design is experimental and that the teacher may therefore later use information garnered during the course for research publications related to the pilot study. 
A consent form has been attached to the anonymous student feedback forms. Students have had the opportunity to deny that their anonymous written feedback be used for research purposes (only one student did not return a positive consent form).

The first course in 2015 was a trial, on the basis of which I refined the teaching concept. Based on student feedback, the concept is now mature in the sense that after the last course students found little to improve in the concept. Many students either left the areas to improve -section blank or noted that they could not think of any way that the concept could be further refined. The areas where small improvements could still be made were mainly related to choice of course reading materials and how to activate students in online discussions. The last course also garnered an unusually high average score for all the evaluated areas (4.83/5.00). A summary of the numerical course feedback from all three years is presented in Table 3 . 
Table 3. Summary of course feedback 2015-17

\begin{tabular}{lcc}
\hline & $\begin{array}{c}\text { Point } \\
\text { average } \\
\text { (scale from } \\
\mathbf{1 - 5})\end{array}$ & $\begin{array}{c}\text { As \% of } \\
\text { maximum } \\
\text { score }\end{array}$ \\
\hline Course content & 4.60 & $92.0 \%$ \\
Technical implementation & 4.36 & $87.2 \%$ \\
\hline Teacher expertise & 4.95 & $99.0 \%$ \\
\hline Teaching style & 4.56 & $91.2 \%$ \\
Course as a whole & 4.57 & $91.4 \%$ \\
Average & 4.61 & $92.2 \%$ \\
\hline $\begin{array}{l}\text { Student responses }(\boldsymbol{n}) \text { and } \\
\text { response rate }\end{array}$ & 42 & $93.3 \%$ \\
\hline
\end{tabular}

Note: In the feedback form, an equidistant Likert-type scale from 1-5 has been used, where 1 signifies poor and 5 excellent $(\mathrm{n}=210$ separate grades). This scale was used as students' own course performances are graded with the same scale. It is, therefore, both familiar to them and widely used.

The course evaluation has consistently been better than for other courses that I have taught at the same department at the same time (students overlap). In particular, the 4.83 average evaluation for the last game course is extraordinarily high both in absolute terms and in relation to other lecture courses. Typically, even the best and most popular courses tend 
to have an average evaluation in the range of $4.30-4.40$.

In the written sections of feedback forms, students have expressed in numerous ways that the teaching concept works well. In a subjective evaluation of whether students think that they have learned the contents better through the game-based course, compared to a regular lecture course or independent reading of course material, almost all students have indicated that the course concept works better. Slightly more students said that they would have learned as well also through independent study (Table 4).

Students have appreciated, in particular, the interactive nature of the course, the variety in teaching and learning methods used, as well as a generally positive and encouraging atmosphere conducive to learning. While many students "confess" to having been initially attracted to the course mainly because of the possibility to play DIPLOMACY, often such feedback has been accompanied by comments saying that, in fact, they ended up learning more than they initially expected also about the subject matter. 
Table 4. Course design compared to alternative learning options (open-ended questions on student feedback form)

\begin{tabular}{|l|c|c|c|}
\hline & Yes & $\begin{array}{c}\text { Equally well or } \\
\text { ambivalent }\end{array}$ & No \\
\hline $\begin{array}{l}\text { Do you think you learned the } \\
\text { taught material better in this } \\
\text { course compared to a more } \\
\text { traditional lecture course? } \\
\text { Why? }\end{array}$ & 40 & 1 & $(2.4 \%)$ \\
\hline $\begin{array}{l}\text { Do you think you learned the } \\
\text { taught material better in this } \\
\text { course compared to reading } \\
\text { the same study material } \\
\text { independently from } \\
\text { textbooks? Why? }\end{array}$ & $(85.2 \%)$ & $(2.4 \%)$ & - \\
\hline
\end{tabular}

Note: As these were open-ended questions, students did not necessarily answer just with a simple yes / no. Instead, students provided their view on why the course was (or was not) better than the alternative, so answers have been interpreted. In most cases, the answers were clear-cut. If answers were ambivalent or argued both ways, they are counted in the second bracket.

${ }^{\mathrm{i}}$ The only student who gave a clear no-answer added that this was mainly because of her own challenging life situation, which did not allow her to fully concentrate on her studies.

Activity on the course has also been high, with attendance levels far beyond a normal 
lecture course. ${ }^{1}$ The high activity level and motivation of students is essential, as a successful use of simulations in teaching requires that all, or at least most, of students are motivated to attend (Moizer et al., 2009; Asal, 2005). The risk of low attendance was reduced by pre-registration and compulsory attendance. However, probably just as effective as these means was the fact that many students registering for the course had heard positive things about the course in advance from other students. ${ }^{2}$ Students showed a high level of commitment and took ownership of their own learning experience-factors which in educational research have been shown to promote learning (Carini et al., 2006; Vermunt, 2007).

The high attendance requirements, in conjunction with the game limitations themselves also mean that the number of students attending the course cannot easily be raised from the current level of 14-16 students. It should also be noted that the course is quite demanding for students and an intense experience. Overall, student feedback

\footnotetext{
${ }^{1}$ Student absence ratios have been $3.0 \%, 10.0 \%$ and $3.9 \%$, mainly due to sickness and prearranged travel.

${ }^{2}$ The course garnered media attention by a story featured on the main national evening TV news and in two local news articles. The course was also nominated for the University's Course of the Year Prize, being a runner-up in the competition and earning a special mention by the university teaching council.
} 
indicates that the course is thought of as rewarding and highly educative, but also emotionally exhausting.

\section{Changing the Rules of the IR Game}

This article has described an elective IR teaching course applying the DIPLOMACY board game that I have designed and taught at the undergraduate level for three consecutive years. I utilized DIPLOMACY in a manner that involves all three elements of real diplomacy: negotiation, signaling and public diplomacy (Rourke, 1999). In my experience, DIPLOMACY enables the teacher to concretely illustrate several central and cumbersome problems intimately related to the field. For example, how difficult it is to establish and maintain trust, and how easy it is to lose trust. Or how difficult it is to construct workable and durable international cooperation when interests are opposite and no higher instance enforces agreements (that is, no court system or world government). Students get hands-on experience in making difficult decisions under time-pressure and circumstances where no optimal solutions are available. The influence of cognitive limitations (for example, preconceptions, bounded rationality, prejudices and heuristic fallacies) on decision-making will also be readily apparent, enabling students to reflect on issues pertinent to the subfield of foreign policy analysis (Hudson, 2014; Allison, 1971). 
While others have also used DIPLOMACY in IR teaching, this article focused on how I altered game play in order to make it more suitable for IR education. Through a comprehensive, integrative and interactive course design, I attempted to overcome a common shortcoming of using games in teaching, that is, that their relationship to the educational aims is only tangential, or that playing the game comes to dominate over the learning objectives. The second area of changes relates to more specific concerns of IR teaching, as well as the nature of DIPLOMACY itself. To make the game more useful for IR teaching, I introduced four specific modifications: 1) team play, 2) a dedicated peace mediator team, 3) altered win rules, and 4) post-game discussion of the Wendtian notion of cultures of anarchy.

Through these four game modifications, students were able to turn a game that is infamous for its backstabbing and breaking of promises into a game that resolves in a mediated and negotiated peaceful agreement. By altering the rules, students were able to overcome the gamer mode trap of behaving very differently (for example, more aggressively or deceptively) in the game than they would in real life (Frank, 2012). If we regard DIPLOMACY as a microworld simulation of real international relations, these findings suggest that by the described tweaks to the game, DIPLOMACY can be useful in IR teaching beyond imparting the (offensive) realist worldview. 
The field of international relations was born out of the carnage of the First World War, grew up in the shadow of the Second World War and matured during the Cold War. Issues of war and peace are integral to the endeavor, and normative considerations never far away. It matters how we teach our students about the field. Instead of teaching as if real-world international relations were subject to some timeless and objective laws of state-centered realism, it is more fruitful to let students experience first-hand how compelling the logic of realism can be when international relations have been structured along self-help lines, and then let them understand that this is but one way of structuring relations between states and other actors, and by no means inevitable.

\section{References}

Allison, G. (1971). Essence of decision: Explaining the Cuban missile crisis. Boston: Little Brown. Asal, V. (2005). Playing games with international relations. International Studies Perspectives, 6, 359-373. doi: 10.1111/j.1528-3577.2005.00213.x

Brown, S. W. \& King, F. B. (2000). Constructivist pedagogy and how we learn: Educational psychology meets International Studies. International Studies Perspectives, 1 (3), 245-254. doi: $10.1111 / 1528-3577.00025$

Bull, H. (1977 [1995]). The Anarchical Society. A Study of Order in World Politics, 2. edition. New York, NY: Columbia University Press. 
Calhamer, A. B. (1999). Calhamer on DIPLOMACY. The boardgame "DIPLOMACY" and diplomatic history, 2. edition. Bloomington, IN: Authorhouse.

Carini, R. M., Kuh, G. D. \& Klein, S. P. (2006). Student engagement and student learning: Testing the linkages. Research in Higher Education, 47 (1), 1-32. doi: 10.1007/s11162-005$8150-9$

Coghlan, C. L., \& Huggins, D. W. (2004). That's not fair! A simulation exercise in social stratification and structural inequality. Teaching Sociology, 32, 177-187. doi: 10.1177/0092055X0403200203

Cooper, R. (2000). The post-modern state and the world order. Demos.

Crookall, D. (2010). Serious games, debriefing, and simulation/gaming as a discipline. Simulation \& Gaming, 41 (6), 898-920. doi:10.1177/1046878110390784

Drake, P. \& Sung, K. (2011). Teaching introductory programming with popular board games. Proceedings of the 42nd ACM techncial symposium on Computer science education, 619624. doi: $10.1145 / 1953163.1953338$

Eskin, B. (2004). World domination: the game. Washington Post, 14.11.

Frank, A. (2012). Gaming the game: A study of the gamer mode in educational wargaming. Simulation \& Gaming, 43 (1), 118-132. doi: 0.1177/1046878111408796

Gattie, G. (2004). Investigating dynamic environments using the game of DIPLOMACY. Proceedings of the Human Factors and Ergonomics Society $48^{\text {th }}$ Annual meeting. 
Hess, F. M. (1999). Bringing the social sciences alive. Needham Heights, MA: Allyn and Bacon.

Hoy, B. (2018). Teaching history with custom-built board games. Simulation \& Gaming, doi: $10.1177 / 1046878118763624$

Huang, A. \& Levinson, D. (2012). To game or not to game. Transportation Research Record: Journal of the Transportation Research Board, 2307, 141-149. doi: 10.3141/2307-15

Hudson, V. M. (2014). Foreign policy analysis. Classic and contemporary theory, 2. edition. Lanham, MD: Rowman \& Littlefield.

Johnston, A. I. (1995). Cultural Realism: Strategic Culture and Grand Strategy in Chinese History. Princeton: Princeton University Press.

Kauneckis, D. L. and Auer, M. R. (2013). A simulation of international climate regime formation. Simulation \& Gaming, 44 (2-3), 302-327. doi: 10.1177/1046878112470542

Kissinger, H. (1994). Diplomacy. London: Simon \& Schuster.

Kuperman, R. D. (2010). Analyzing conflict dynamics with the aid of an interactive microworld simulator of a fishing dispute. Simulation \& Gaming 41 (3), 293-315. doi: $10.1177 / 1046878109341397$

Loggins, J. (2009). Simulating the foreign-policy decision-making process in the undergraduate classroom. PS: Political Science \& Politics, 42 (2), 401-407. doi: $10.1017 / \mathrm{S} 1049096509090544$ 
Mason, R. \& Patterson, E. (2012). War gaming peace operations. Simulation \& Gaming, 44 (1), 118-133. doi: $10.1177 / 1046878112455490$

Mayer, I. S. (2009). The gaming of policy and the politics of gaming. Simulation \& Gaming, 40 (6), 825-862. doi: 10.1177/1046878109346456

Mearsheimer, J. J. (2001). The Tragedy of Great Power Politics. New York, NY: W. W. Nortion \& Company.

Moizer, J., Lean, J., Towler, M. \& Abbey, C. (2009). Simulations and games. Overcoming the barriers to their use in higher education. Active Learning in Higher Education, 10 (3), 207224. doi: $10.1177 / 1469787409343188$

Männarmaa, I. (2015). FOUNTAINS. Table-top simulation game on acculturation strategies. Simulation \& Gaming 46 (1), 113-126. doi: 10.1177/1046878115591248

Niv-Solomon, A. et al (2009). Evolving beyond self-interest? Some experimental findings from simulated international negotiations. Simulation \& Gaming, 42 (6), 711-732. doi: $10.1177 / 1046878109341764$

Paino, M. \& Chin, J. (2011). MONOPOLY and critical theory: Gaming in a class on the sociology of deviance. Simulation \& Gaming 42 (5), 571-588. doi: $10.1177 / 1046878110391022$

Putnam, R. D. (1988). Diplomacy and domestic politics: The logic of two-level games. International Organization 42 (3), 427-460. doi: 10.1017/S0020818300027697 
Rieber, L. P. (1996). Designing interactive learning environments based on the blending of microworlds, simulations and games. Educational Technology Research and Development, 44 (2), 43-58. doi: 10.1007/BF02300540

Rieber, L. P. \& Noah, D. (2008). Games, simulations, and visual metaphors in education: Antagonism between enjoyment and learning. Educational Media International, 45, 77-92. doi: $10.1080 / 09523980802107096$

Romme, A. G. L. (2004). Perceptions of the value of microworld simulation: Research Note. Simulation \& Gaming, 35 (3), 427-436. doi: 10.1177/1046878103261916

Rourke, J. T. (1999). International Politics on the World Stage, $2^{\text {nd }}$ ed. Boston, MA: Dushkin/McGraw-Hill.

Tamai, M., Kondo, A. and Miyawaki, N. (2016). Understanding the history of international politics: Retrospective and repeated type of gaming and simulation in the classroom. Simulation and gaming in the network society conference proceedings, 133-145.

Tickner, J. A. (2005). What is your research program? Some feminist answers to international relations methodological questions. International Sudies Quarterly, 49, 1-21. doi: $10.1111 /$ j.0020-8833.2005.00332.x

Trager, R. F. (2017). Diplomacy. Communication and the Origins of International Order. Cambridge: Cambridge University Press. 
Vermunt, J. D. (2007). The power of teaching-learning environments to influence student learning. In Student Learning and University Teaching, BJEP Monograph Series II, 4, 7390. doi: 10.1348/000709906X162406

Weir, K. \& Baranowski, M. (2011). Simulating history to understand international politics. Simulation \& Gaming, 42 (4), 441-461. doi: 10.1177/1046878108325442

Wendt, A. (1999 [2010]). Social Theory of International Politics, 13. edition. Cambridge: Cambridge University Press.

Wight, M. (1991). The three traditions of international theory. In G. Wight and N. Porter, eds, International Theory: The Three Traditions. Leicester: Leicester University Press, 7-24.

Zagal, J. P., Rick, J. and His, I. (2006). Collaborative games: Lessons learned from board games. Simulation \& Gaming, 37 (1), 24-40. 